\title{
Number of Full Term Pregnancies
}

National Cancer Institute

\section{Source}

National Cancer Institute. Number of Full Term Pregnancies. NCI Thesaurus. Code C158621.

The number of full term pregnancies. 